\title{
Especificidade de Anti-soro Policlonal à Leifsonia xyli subsp. xyli
}

\author{
Josil B. Carneiro Jr¹, Silvaldo F. da Silveira², Gonçalo A. de Souza Filho ${ }^{3}$, Fabio L. Olivares ${ }^{4}$ \\ \& Éder A. Giglioti ${ }^{5}$
}

${ }^{1}$ Laboratório de Fitopatologia, Campus Dr. Leonel Miranda, Universidade Federal Rural do Rio de Janeiro, CEP 28000-138, Campos dos Goytagazes, RJ, e-mail: josilsan@aol.com; ${ }^{2}$ Laboratório de Proteção de Plantas (CCTA), ${ }^{3}$ Laboratório de Biotecnologia (CBB), ${ }^{4}$ Laboratório de Biologia Celular e Tecidual (CBB), Universidade Estadual do Norte Fluminense, CEP 28013-620, Campos dos Goytagazes, RJ, ${ }^{5}$ Laboratório de Fitopatologia Molecular e Engenharia Genética, Universidade Federal de São Carlos, Araras, SP, CEP 13600-970

(Aceito para publicação em 14/11/2003)

Autor para correspondência: Josil de Barros Carneiro Junior

CARNEIRO, J.B., SILVEIRA, S.F., DE SOUZA FILHO, G.A., OLIVARES, F.L. \& GIGLIOTI, E.A. Especificidade de anti-soro policlonal à Leifsonia xyli subsp. xyli. Fitopatologia Brasileira 29:614-619. 2004.

\section{RESUMO}

Detectar a presença da bactéria Leifsonia xyli subsp. xyli em material de propagação da cana-de-açúcar (Saccharum sp.) é importante para direcionar o controle do raquitismo-da-soqueira. Neste trabalho, objetivou-se produzir anticorpo policlonal específico contra Leifsonia xyli subsp. xyli (Lxx), visando utilizá-lo em método sorológico para detecção do patógeno. Para isso, o antígeno foi preparado a partir de células intactas, após lavagem por centrifugação de cultura-pura em tampão fosfato salino $0,01 \mathrm{M}$ (PBS) e diálise em glutaraldeido $2 \%$ em PBS. O plano de imunização em coelho consistiu de duas injeções intramusculares da mistura 1:1 do antígeno com adjuvante Freund (completo e incompleto, a intervalos de 21 dias) e duas injeções subcutâneas do antígeno puro, a intervalos de dez dias. O anti-soro foi testado pelo método de Dot Blot com revelação por peroxidase para se determinar: (i) título do anticorpo e (ii) reação contra Lxx, Xanthomonas axonopodis pv. vesicatoria e bactérias endofíticas de cana-de-açúcar (Azospirillum brasilense, A. lipoferum, Herbaspirillum rubrisubalbicans, H. seropedicae e Gluconacetobacter diazotrophicus). A maior diluição analisada do anti-soro 1:20.000 mostrou reação fortemente positiva e específica contra $L x x$ e ausência de reação contra as demais bactérias. A purificação da fração IgG (Imunoglobulina $G$ ) não resultou em melhoria na reatividade e especificidade do anti-soro. Estimou-se o nível de detecção do método a partir de suspensão bacteriana em $2 \times 10^{6}$ células $/ \mathrm{ml}$.

Palavras-chave adicionais: sorologia, dot-blot, raquitismo da soqueira, Saccharum sp.

\section{ABSTRACT}

Policlonal antiserum specifity against Leifsonia xyli subsp. xyli To detect the presence of the bacterium Leifsonia xyli subsp. $x y l i(L x x)$ in propagation material is important for the control of the ratoon stunting disease. The objective of this work was to improve a serological method for detection of the pathogen and to evaluate the policlonal antiserum specificity produced against $L x x$. The antigen was prepared by resuspending pure culture in PBS and dialyzing it in glutaraldehyde $2 \%$ in PBS. The immunization schedule in rabbit constituted of two intramuscularly injections of 1:1 mixture of the antigen: Freund adjuvant (complete and incomplete, with interval of 21 days) and two subcutaneous injections of the antigen, with ten-day intervals. The antiserum was tested by Dot Blot and revealed by peroxidase to determine: (i) title of the antibody, (ii) reaction and specificity against Lxx, Xanthomonas axonopodis pv. vesicatoria and endophytic sugarcane (Saccharum sp.) bacteria (Azospirillum brasilense, A. lipoferum, Hebaspirillum rubrisubalbicans, H. seropedicae, Gluconacetobacter diazotrophicus). The highest dilution of antiserum (1:20.000) presented strong positive reaction and high specificity against $L x x$. The purification of the IgG fraction did not improve the antiserum reactivity and specificity. In bacterial cell suspension the level of detection was estimated in $2 \times 10^{6}$ cells $/ \mathrm{ml}$.

\section{INTRODUÇÃO}

A cultura da cana-de-açúcar (Saccharum sp.) é a principal atividade agrícola da região Norte Fluminense com área plantada de 126 mil hectares e produtividade de $46 \mathrm{t}$ de colmos/ha (CIDE, 2000). Dentre os fatores que afetam negativamente a produtividade da cana-de-açúcar na região, podem ser citados: deficiência hídrica, cultivo de variedades ultrapassadas e ocorrência de pragas e de doenças. Das doenças, destaca-se o raquitismo-da-soqueira da cana-deaçúcar (do inglês: Ratoon Stunting Disease - RSD), causado pela bactéria Leifsonia xyli subsp. xyli - Lxx (Davis et al., 1980, 1984; Evtushenko et al., 2000). Esta doença foi constatada no Brasil pela primeira vez no município de Campos dos Goytacazes, RJ, por Frederico Veiga, em 1956. Em ensaios realizados em solos de tabuleiro na região de Macaé-RJ, os danos causados por RSD foram estimados em $21 \%$ (em toneladas de cana por hectare) (Chagas \& Matsuoka, 1988).

Leifsonia xyli subsp. xyli encontra-se classificada no grupo corineforme, sendo gram-positiva, aeróbica, pleomórfica e fastidiosa. Produz in vitro colônias minúsculas 
e translúcidas, após 14 dias de cultivo em meio SC - Soybean Corn (Gillaspie et al., 1981; Cardoso, 1986). Dificuldades para o isolamento e para o cultivo in vitro atrasaram a identificação do agente etiológico da doença (Davis et al., 1980) e, conseqüentemente, a seleção de genótipos de canade-açúcar resistentes ou tolerantes.

A falta de sintomas característicos e específicos foi o principal motivo para a disseminação de $L x x$ em todas as regiões canavieiras do mundo (Cardoso, 1986). Pelo mesmo motivo, a diagnose da doença só pode ser feita pela detecção do patógeno (Sanguino et al., 1984, 1998). Para detecção de Lxx por métodos sorológicos faz-se necessária a produção de anticorpo específico contra o patógeno. A maioria dos trabalhos recentes que empregam sorologia para a diagnose do RSD enfoca mais a comparação de técnicas sorológicas do que a produção e a qualidade do anti-soro produzido (Gillaspie, 1978; Gillaspie \& Harris, 1979; Harrison \& Davis, 1986, 1990; Guzmán \& Victoria, 1993). Até o momento não se testou a possibilidade do anti-soro purificado ou bruto reagir contra outras bactérias endofíticas naturais da cana-de-açúcar, as quais são comumente encontradas colonizando raízes, folhas e colmos (Oliveira, 2000). Neste trabalho, objetivouse produzir anticorpo policlonal específico contra $L x x$, avaliar a especificidade do anti-soro produzido, em sua forma bruta e purificada, bem como a possibilidade de haver reações cruzadas com outras bactérias endofíticas naturais de canade-açúcar.

\section{MATERIAL E MÉTODOS}

\section{Cultivo da bactéria $L x x$}

Nos ensaios sorológicos foi utilizada cultura pura de Lxx isolada da variedade de cana-de-açúcar SP 70-1284 (Vicente Moraes, Técnico Superior da Copersucar, informação pessoal). Para o cultivo de $L x x$ foi utilizado o meio Soybean Corn (Gillaspie et al., 1981; Cardoso, 1986), que foi preparado em duas partes, tendo sido a primeira parte autoclavada a $121{ }^{\circ} \mathrm{C} / 15$ min e a segunda esterilizada por filtração. A parte autoclavada foi constituída por $17 \mathrm{~g}$ de cornmeal-ágar $\left(\right.$ Gibco $\left.^{\circledR}\right), 8 \mathrm{~g}$ de peptona de soja (Biobrás ${ }^{\circledR}$ ), $4 \mathrm{~g}$ de ágar $\left(\right.$ Sigma $\left.^{\circledR}\right), 1 \mathrm{~g}$ de fosfato de potássio monobásico, $1 \mathrm{~g}$ de fosfato de potássio dibásico, 0,2 g de sulfato de magnésio heptahidratado, dissolvidos em $925 \mathrm{ml}$ de água destilada, adicionando-se, ainda, $15 \mathrm{mg}$ de hemina bovina (Inlab ${ }^{\circledR}$ ) (previamente dissolvida em $15 \mathrm{ml}$ de solução $0,05 \mathrm{~N}$ de $\mathrm{NaOH}$ ). $\mathrm{O}$ pH desta parte do meio foi ajustado a 6,3 a 6,5 antes de autoclavar. A parte esterilizada por filtração foi preparada com $1,0 \mathrm{~g}$ de cisteína $\mathrm{HCl}\left(\operatorname{Vetec}^{\circledR}\right.$ ) e $0,5 \mathrm{~g}$ glicose dissolvidas em $60 \mathrm{ml}$ de água destilada. Em seguida, ajustouse o pH para 6,2, e se adicionou $1 \mathrm{~g}$ de albumina bovina $\left(\right.$ Sigma $\left.^{\circledR}\right)$.

A bactéria foi cultivada em temperatura variando de $28-30{ }^{\circ} \mathrm{C}$, mantendo-se a umidade no interior da incubadora entre 80 - 85\% com bandejas d'água, para evitar desidratação do meio. Colônias de $0,1 \mathrm{~mm}$ de diâmetro foram observadas entre duas e três semanas de incubação.

\section{Material biológico utilizado na avaliação do anti-soro}

Para avaliar a especificidade do anti-soro foi utilizada uma cultura de Xanthomonas axonopodis pv. vesicatoria (Batista, 1947) incubada em meio DYGS (Rodrigues Neto et al.,1986) e as bactérias endofíticas de cana-de-açúcar: Azospirillum brasilense (Tarrand et al., 1978), Azospirillum lipoferum (Tarrand et al., 1978), Herbaspirillum rubrisubalbicans (Bandani et al., 1996), Herbaspirillum seropedicae (Baldani et al., 1986) e Gluconacetobacter diazotrophicus (Gillis et al., 1989) incubadas em meio DYGS líquido, cedidas pelo Laboratório de Biologia Celular e Tecidual da Universidade Estadual do Norte Fluminense e isoladas originalmente pela Embrapa - Agrobiologia, RJ.

Visando avaliar a capacidade de detecção do anti-soro em seiva do xilema, foram coletadas amostras de colmos de cana-de-açúcar: amostra 1 - Co 421, cana-soca inoculada com suspensão de células de $L x x$ em cana-planta; amostra 2 RB 758540, cana-soca, e amostra 3 - RB 72454, cana-soca de campo comercial infetada, de acordo com análise realizada pela Copersucar.

\section{Confirmação específica de Leifsonia xyli subsp. xyli pela morfologia das células, característica da cultura e teste de patogenicidade}

A suspensão bacteriana foi preparada para microscopia, em tampão fosfato salino (PBS $=0,01 \mathrm{M} \mathrm{K}_{2} \mathrm{PO}_{4}$ $+\mathrm{KPO}_{4}, \mathrm{pH} 7,0, \mathrm{NaCl}$ 0,85\%). A bactéria foi visualizada em microscópio ótico (Zeiss Azioplan ${ }^{\circledR}$ ) por meio de contraste diferencial e interdiferencial, sob aumento de 1.200 vezes (James et al., 1994), colocando-se uma gota da suspensão bacteriana em PBS sob parafilme e, a seguir, flutuando em uma grade de cobre de $200 \mathrm{mesh}$, por $1 \mathrm{~min}$. Decorrido este período, a grade foi seca em papel filtro, sendo usado como contraste solução aquosa de ácido fosfotúngstico $1 \%$, por 1 min (Olivares, 1997). Após a fixação, a amostra foi lavada por três vezes em água destilada e deixada secar por $90 \mathrm{~min}$ em papel filtro (James et al., 1994). As células de Lxx foram observadas ao microscópio eletrônico de transmissão (ZEISS EM $900^{\circledR}$ ) no aumento de 30.000 vezes. A forma das colônias e o crescimento lento em meio SC foram utilizados como critérios para a confirmação específica de $L x x$. Foi realizado também um teste de patogenicidade inoculando a suspensão bacteriana de $L x x$ (colônias de $L x x$ ressuspendidas em PBS) através de injeções com $1 \mathrm{ml}$ no terceiro internódio basal de aproximadamente 50 plantas da variedade Co 421, suscetível ao RSD.

\section{Produção do anti-soro}

O antígeno foi preparado a partir de células intactas de Lxx. Para isso, as colônias em meio líquido foram centrifugadas a $10.000 \mathrm{rpm}$, durante $20 \mathrm{~min}$ e ressuspensas em tampão fosfato salino (PBS). Após nova centrifugação e ressuspensão em PBS (lavagem), as células foram dialisadas (por duas vezes) à noite $(12 \mathrm{~h})$ e a frio $\left(4^{\circ} \mathrm{C}\right)$, em solução de glutaraldeído 2\% (preparada em PBS) e em PBS puro, respectivamente (Guzman \& Victoria, 1993). O antígeno foi 
armazenado em freezer $\left(-20^{\circ} \mathrm{C}\right)$. A concentração do antígeno foi ajustada para densidade ótica de 0,2 de absorvância a 600 nm, antes da injeção nos coelhos (raça Nova Zelândia branco). Foram aplicadas quatro injeções de $2 \mathrm{ml}$, sendo que na primeira utilizou-se antígeno com adjuvante completo de Freund (1:1) e, na segunda, adjuvante incompleto de Freund (1:1). As duas primeiras aplicações foram intramusculares e com intervalos de 21 dias. As últimas duas injeções foram subcutâneas, com $2 \mathrm{ml}$ de antígeno puro e com dez dias de intervalo. Foram realizadas duas coletas de sangue, aos sete dias após a terceira e quarta injeções. O sangue foi armazenado em geladeira por $12 \mathrm{~h}$ e, posteriormente, centrifugado a 2.500 $\mathrm{rpm}$, durante $15 \mathrm{~min}$, para retirada do plasma (anti-soro bruto). $\mathrm{O}$ anti-soro bruto foi armazenado em freezer, a -20 ${ }^{\circ} \mathrm{C}$.

\section{Purificação da fração IgG}

$\mathrm{O}$ anti-soro foi purificado adicionando-se, gota a gota, solução saturada de sulfato de amônia $\left(\mathrm{NH}_{4}\right) \mathrm{SO}_{4}$ a $2 / 3$ do volume inicial do plasma, durante $2 \mathrm{~h}$, sob agitação manual. Em seguida, centrifugou-se por duas vezes consecutivas a $10.000 \mathrm{rpm}$, durante $20 \mathrm{~min}$, ressuspendendo o precipitado em PBS. A suspensão resultante foi dialisada por $48 \mathrm{~h}$, a frio, em solução de PBS, para remoção do excesso de sulfato de amônia. Em seguida, centrifugou-se a 10.000 rpm, durante 20 min, para a remoção de precipitados. O sobrenadante (IgG) foi armazenado em freezer, a - $20{ }^{\circ} \mathrm{C}$ (Guzman \& Victoria, 1993).

\section{Reatividade do anti-soro em diferentes diluições}

O título do anti-soro bruto da primeira sangria foi determinado avaliando-se a reação contra as bactérias $L x x e$ $X$. axonopodis pv. vesicatoria (Xav). As suspensões bacterianas foram ajustadas para a densidade ótica de 0,2 absorbância $(600 \mathrm{~nm})$ que correspondem $1 \times 10^{8}$ células $/ \mathrm{ml}$ (Guzmán \& Victoria, 1993). O anti-soro foi analisado nas diluições de 1:100, 1:500, 1:1.000, 1:5.000, 1:10.000, efetuando-se o ensaio de Dot Blot. Após a segunda sangria determinou-se novamente o título, a reatividade e a especificidade dos anti-soros purificado e bruto. Foram testadas as diluições 1:1.000, 1:5.000, 1:10.000, e 1:20.000 dos anti-soros. As suspensões bacterianas estavam com concentrações diferentes ( $L x x \operatorname{com} 4 \times 10^{7}$ células bacterianas/ $\mathrm{ml}$ e $X a v$ com $6,6 \times 10^{8}$ células bacterianas $\left./ \mathrm{ml}\right)$. Foram também utilizadas as amostras 1,2 e 3 de seiva do xilema. $\mathrm{Na}$ membrana foram aplicados $10 \mu \mathrm{l}$ de cada amostra, inclusive das suspensões bacterianas.

\section{Análise da especificidade do anti-soro}

A reatividade do anti-soro bruto contra $L x x$ e bactérias endofíticas da cana-de-açúcar (A. brasilense, A. lipoferum, $H$. rubrisubalbicans, $H$. seropedicae e G. diazotrophicus) foi avaliada. As suspensões bacterianas foram ajustadas na densidade de $7 \times 10^{7}$ células bacterianas $/ \mathrm{ml}$ para as bactérias endofiticas e para 4 e $7 \times 10^{7}$ células bacterianas $/ \mathrm{ml}$ para $L x x$. As suspensões de $L x x$ foram ainda diluídas 1:10, 1:20,
1:50, 1:100, 1:200 e 1:1.000 em PBS. Primeiramente, a coloração da membrana com Ponceau (Ponceau 0,1\% em ácido acético $0,5 \%$ ) foi efetuada para estimar visualmente a densidade de proteínas das amostras aplicadas na membrana. Após lavagem da membrana, realizou-se o ensaio de Dot Blot, utilizando-se, para isso, anti-soro bruto diluído 20.000 vezes.

\section{Ensaio de Dot Blot}

O ensaio sorológico foi iniciado com a hidratação da membrana de nitrocelulose $\left(\right.$ Sigma $\left.{ }^{\circledR}\right)$ com água ultra-pura (Mili-Q), por $10 \mathrm{~min}$. As amostras foram aplicadas na membrana sob vácuo. Em seguida, a membrana foi bloqueada por $1 \mathrm{~h}$ em solução tampão TS (tris base $100 \mathrm{mM}, \mathrm{pH}$ 7,4; $\mathrm{NaCl}$ 1,5 M; tween 20 0,5\%) com $0,3 \%$ de leite em pó desnatado, lavando-se logo após, em solução tampão TS, por três vezes, durante 10 min cada. A membrana foi incubada em solução de anti-soro bruto (nas diluições 1:1.000, 1:5.000, $1: 10.000$ e 1:20.000 com solução tampão TS com $0,1 \%$ de leite em pó) por $1 \mathrm{~h}$ e, novamente lavada em tampão TS, por três vezes, durante $10 \mathrm{~min}$. Em seguida, a membrana foi incubada por $2 \mathrm{~h}$ na presença de proteína-A conjugada a peroxidase e diluída 1:2.000 em solução tampão TS com $0,1 \%$ de leite em pó. Foram repetidas as três lavagens sucessivas em tampão TS, 10 min cada, e mais uma vez por $15 \mathrm{~min}$ em PBS. O processo sorológico foi finalizado no escuro, mantendo-se a membrana por 5 min em solução reveladora (tris-base $40 \mathrm{mM}, \mathrm{pH} 7,4$, imidazol 10mM, diaminobendizina $1 \mathrm{mg} / \mathrm{ml}$, peróxido de hidrogênio $0,5-1,0 \mu \mathrm{l} / \mathrm{ml}$ ). Todo o processo sorológico foi conduzido sob agitação e à temperatura ambiente.

\section{RESULTADOS}

Confirmação específica de Leifsonia xyli subsp. xyli por meio da morfologia das células, características das culturas e teste de patogenicidade

A forma das colônias (pequenas e translúcidas), o crescimento lento e o tamanho reduzido das células bacterianas, bem como a forma de bacilo, irregular e pleomórfico e a ausência de endosporos confirma a identificação do isolado utilizado (Figura 1), conforme descrição de Lxx (Davis et al., 1980, 1984; Evtushenko et al., 2000). Confirmou-se a patogenicidade do isolado utilizado, aos dez meses após a inoculação, alguns colmos apresentaram sintomas característicos da doença, tais como colmos finos e subdesenvolvidos. Aos 25 meses foram observadas muitas plantas subdesenvolvidas (raquíticas) e através do teste sorológico de Dot Blot foi confirmada a presença da bactéria previamente inoculada.

\section{Atividades do anti-soro em diferentes diluições}

Foi observado que o anti-soro bruto da primeira sangria apresentou reação fortemente positiva e específica à $L x x$ na maior diluição testada $(1: 10.000)$. Foi verificada também ausência de reação cruzada contra $X a v$ em todas as diluições do anti-soro (Figura 2). 
Especifidade de anti-soro policlonal contra Leifsonia xyli subsp. xyli

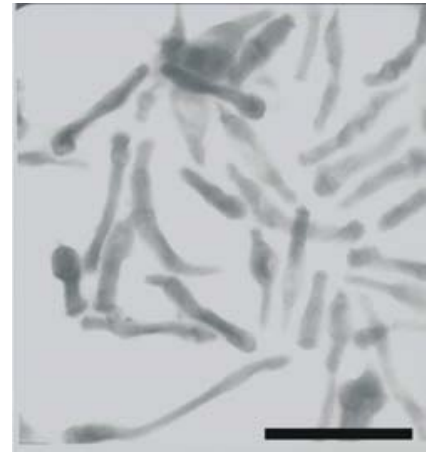

FIG. 1 - Leifsonia xyli susbp. xyli em solução aquosa de ácido fosfotúngstico $1 \%$, aumento de $30.000 \mathrm{x}$ em microscopia eletrônica de transmissão. A barra equivale a 1,0 $\mu \mathrm{m}$.

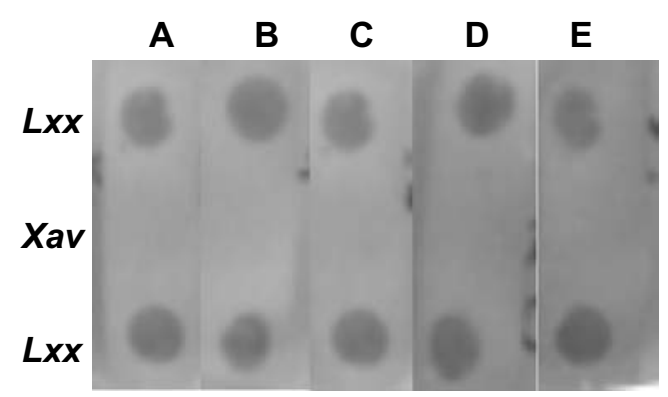

FIG. 2 - Determinação do título do anti-soro bruto. Observam-se as reações positivas contra Leifsonia xyli susbp. xyli $(L x x)$ e ausência de reações contra Xanthomonas axonopodis pv. vesicatoria (Xav). As diluições do anti-soro utilizadas foram: $\mathrm{A}=1: 100, \mathrm{~B}=1: 500$, $\mathrm{C}=1: 1.000, \mathrm{D}=1: 5.000$ e $\mathrm{E}=1: 10.000$.

Os anti-soros purificado e bruto oriundos da segunda sangria mostraram reações positivas contra $L x x$ em todas as diluições testadas, observando-se reações cruzadas contra $\mathrm{Xav}$ nas diluições de 1:1.000, 1:5.000 e 1:10.000 e, praticamente, ausência de reação na diluição $1: 20.000$, tanto para anti-soro purificado quanto para o bruto (Figura 3B).

A forte reação na amostra 1 indicou a presença de $L x x$, o que era esperado, pois a amostra foi coletada de planta inoculada, sendo as reações dos anti-soros (bruto e purificado) leves nas amostras 2 e 3 . A reação positiva para amostra 2 não era esperada, por tratar-se de plantas cujas mudas foram submetidas ao tratamento térmico. A reação positiva para amostra 3 não surpreendeu, pois análise sorológica prévia apresentou reação positiva à $L x x$. A purificação da fração IgG não resultou em melhoria de reatividade e especificidade do anti-soro (Figura 3B).

Pela coloração de Ponceau foram observadas as maiores concentrações de proteínas nas amostras 2, Xav, 1 e 3 e a menor concentração de proteína na amostra de $L x x$, o que indicou que a especificidade do anti-soro não está relacionada com maior densidade de células da bactéria-alvo na membrana (Figura 3A).

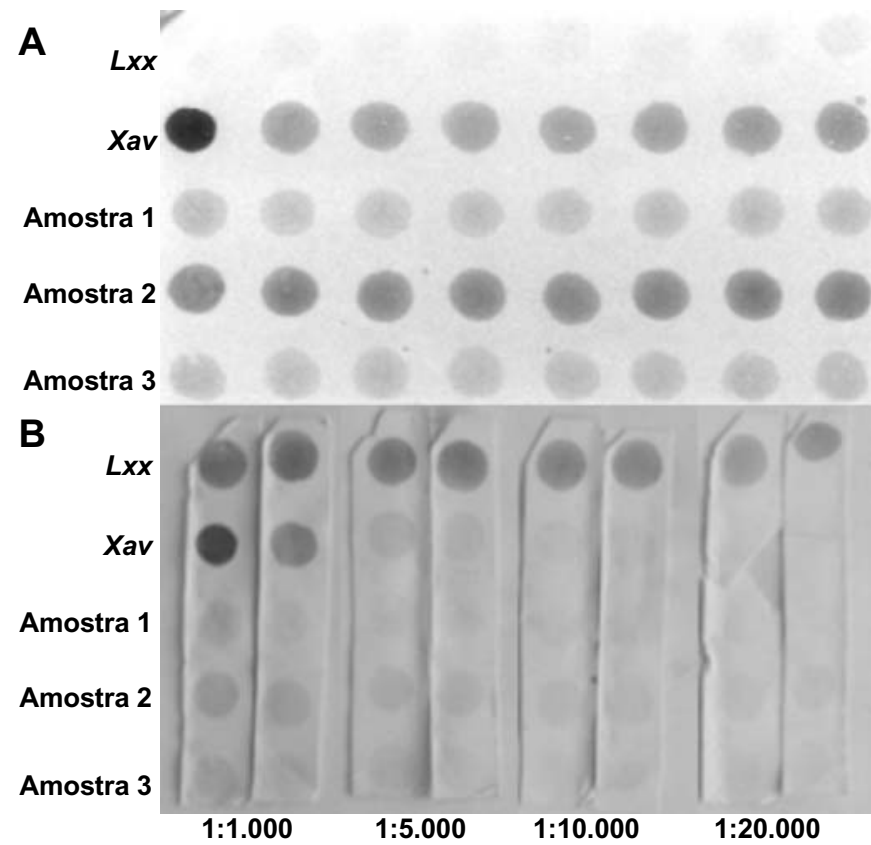

FIG. 3 - Análise da especificidade do anti-soro bruto (primeira fita) e purificado (segunda fita) a Leifsonia xyli susbp. xyli - Lxx. A Coloração de Ponceau. A menor densidade de proteínas encontra-se nas amostras de $L x x ; \mathbf{B}$ - Ensaio Dot Blot: reações positivas fortes contra $L x x$ nas diluições de 1:1.000 até 1:20.000. Reações cruzadas contra Xanthomonas axonopodis pv. vesicatoria - Xav nas diluições 1:1.000 até 1:10.000. Ausência de reação na diluição 1:20.000 do anti-soro contra Xav. Amostra 1 - Co 421, cana-soca tratada termicamente a $50,5^{\circ} \mathrm{C}$ por $2 \mathrm{~h}$ e inoculada com suspensão bacteriana de Lxx; Amostra 2 - RB 758540, cana-soca tratada termicamente a $50,5{ }^{\circ} \mathrm{C}$ por $2 \mathrm{~h}$; Amostra 3 - RB 72454, cana-soca de campo comercial infetado.

\section{Análise da especificidade do anti-soro bruto e purificado}

Reação positiva a $L x x$ até a diluição de 1:20 da suspensão bacteriana foi observada na membrana incubada com anti-soro bruto (diluição de 1:20.000). Não se observaram reações positivas nas amostras das bactérias endofíticas (Figura 4B). Pela coloração de Ponceau foi confirmado que as amostras das bactérias endofíticas apresentavam maiores densidades de proteínas na membrana do que as de Lxx (Figura 4A).

\section{DISCUSSÃO}

O método utilizado para a obtenção do anti-soro foi semelhante ao relatado por Guzmán \& Victoria (1993), porém, o esquema de imunização (preparo do antígeno, intervalos, número e modo de aplicação das injeções) foi modificado. Neste trabalho, optou-se por determinar o título do anti-soro por Dot Blot, pois será o método utilizado na diagnose rotineira de RSD. Assim, as reações fortemente positivas contra $L x x$ na diluição de 1:20.000, foram superiores às observadas por Guzmán \& Victoria (1993) e Gillaspie (1978), que obtiveram títulos de 1:2.560 e 1:1.280, utilizando a técnica 


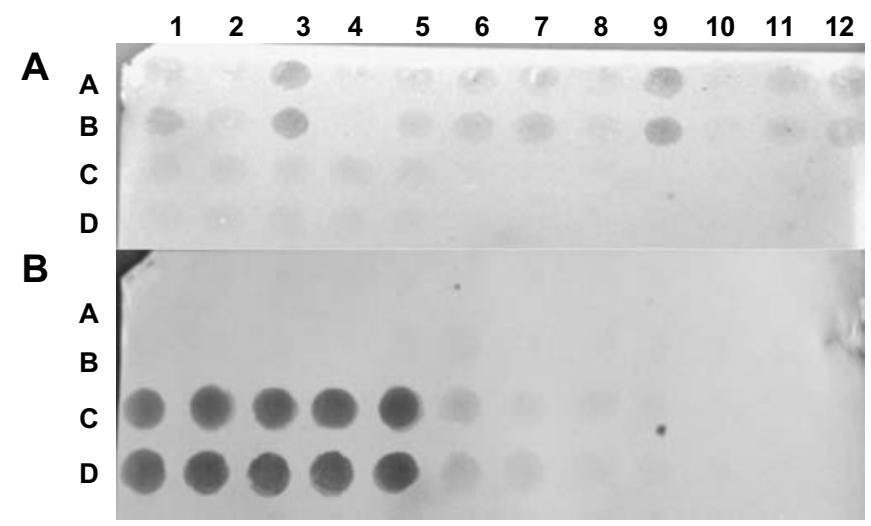

FIG. 4 - Análise da especificidade do anti-soro bruto contra Leifsonia $x y l i$ susbp. $x y l i$ - Lxx. A - Coloração de Ponceau. As densidades de proteínas nas amostras das bactérias endofíticas foram superiores a Lxx. B - Resultado do ensaio de Dot Blot. Reações positivas contra $L x x$ e ausência total de reações contra as bactérias endofíticas. As amostras dispostas em linhas (letras) e colunas (números), constituem:

A1, A7, B1 e B7 - Azospirillum brasilense

A2, A8, B2 e B8 - Gluconacetobacter diazotrophicus

A3, A9, B3 e B9 - 3 e 9 - Herbaspirillum seropedicae

A4, A10, B4 e B10 - H. rubrisubalbicans

A5, A11, B5 e B11 - H. rubrisubalbicans

A6, A12, B6 e B12 - A. lipoferum

$\mathrm{C} 1$ a C5 - $\operatorname{Lxx}\left(4 \times 10^{7}\right.$ células $\left./ \mathrm{ml}\right)$

C6 a C11 - $L x x\left(4 \times 10^{7}\right.$ células $\left./ \mathrm{ml}\right)$ suspensão diluída 10, 20, 50, $100,200,1.000$ vezes

C12 e D12 - solução tampão PBS apenas.

D1 a D5 - $\operatorname{Lxx}\left(7 \times 10^{7}\right.$ células $\left./ \mathrm{ml}\right)$ não diluído

D6 a D11 - $\operatorname{Lxx}\left(7 \times 10^{7}\right.$ células $\left./ \mathrm{ml}\right)$ suspensão diluída 10, 20, 50,

$100,200,1.000$ vezes

de microprecipitação. Apesar das alterações realizadas no protocolo de obtenção do anti-soro e do método de determinação do título resultarem maiores títulos do antisoro produzido, outros fatores devem ser considerados, como por exemplo, as condições do animal utilizado (resposta imunogênica) (Almeida \& Lima, 2001).

Quando se comparou a reatividade do anti-soro bruto com o purificado, não se observou aumento da reatividade nem da especificidade do anti-soro purificado em relação ao anti-soro bruto. A purificação do anti-soro é necessária na técnica de imunofluorescência direta (Guzmán \& Victoria, 1993), pois a fração IgG deve ser conjugada ao pigmento fluorescente (isotiocianato de fluoresceína), o qual pode conjugar-se com contaminantes (proteínas séricas solúveis, lipídios e albuminas) presentes no anti-soro bruto (Almeida \& Lima, 2001). Para os ensaios de Dot Blot, a purificação do anti-soro bruto deve ser descartada, pois se utilizam dois antisoros, um específico contra $L x x$, produzido em coelho, e o outro, reativo contra $\operatorname{IgG}$ de coelho, que é conjugado a enzima reveladora (neste trabalho, proteína A ligada a peroxidase).

Os resultados do ensaio de Dot Blot para avaliar a especificidade mostraram que o anti-soro bruto é altamente específico, pois foi testado contra cinco das sete bactérias diazotróficas já descritas em cana-de-açúcar e não apresentou reação cruzada. O nível de detecção do método de Dot Blot foi estimado em $2 \times 10^{6}$ células bacterianas $/ \mathrm{ml}$ utilizando-se anti-soro bruto, corroborando resultados de literatura (Harrison \& Davis, 1990). Contudo, é uma técnica pouco sensível comparada a imunofluorescência e ao PCR, que detectam em torno de $10^{3}$ a $10^{4}$ células bacterianas/ ml.Todavia, a técnica de Dot Blot apresenta vantagens como rapidez, simplicidade e não necessita de equipamentos mais sofisticados, como microscópio de epifluorescência ou termocicladores, facilitando, assim, seu uso em laboratórios para diagnose rotineira do RSD. Ademais, a técnica é suficientemente sensível para orientar a necessidade do tratamento térmico do material propagativo, no caso de variedades suscetíveis e intolerantes ao RSD.

O método utilizado mostrou-se eficiente, simples e rápido para a produção de anti-soro policlonal, possibilitando a obtenção de um anti-soro altamente reativo e especifico e não necessitando da purificação do anti-soro bruto. A produção do anti-soro específico contra $L x x$ permitiu a implementação de técnicas de diagnose do RSD na região, o que possibilitará novas pesquisas na busca do controle do RSD.

\section{AGRADECIMENTOS}

A COPERSUCAR, nas pessoas de William L. Burnquist e Vicente A.Moraes, por terem fornecido o isolado de $L x x$ e pelas informações sobre o cultivo da bactéria. A UFRRJ pela liberação do primeiro autor, imprescindível para efetuar o curso de pós-graduação. Às Usinas Santa Cruz, São José e Paraíso pelas colaborações ao projeto.

\section{REFERÊNCIAS BIBLIOGRÁFICAS}

ALMEIDA, A.M.R. \& LIMA, J.A.A Princípios e técnicas de diagnose aplicados em Fitovirologia. Publicações $S B F$, Fortaleza, 2001.

BALDANI, J.I., BALDANI, V.L.D., SELDIN, L. \& DOBEREINER, J. Characterization of Herbaspirillum seropedicae gen.nov., a root associated nitrogen fixing bacterium. International Journal of Systematic Bacteriology 36:86-93. 1986.

BALDANI, J.I., POT, B., KIRCHHOF, G., FALSEN, E., BALDANI, V.L.D., OLIVARES, F.L., HASTE, B., KERSTERS, K., HORTMANN, A., GILLIS, M. \& DOBEREINER, J. Emended description of Herbaspirillum, inclusion of (Pseudomonas) rubrisubalbicans, a mild plant pathogen, as Herbaspirillum rubrisubalbicans comb. nov.; and classification of a group of clinical isolates (EF group 1) as Herbaspirillum species 3. International Journal of Systematic Bacteriology 46:802-810. 1996.

BATISTA, A.C. Principais doenças das plantas cultivadas em o Nordeste. Boletim da Secretaria Agricultura, Indústria e Comércio do Estado de Pernambuco 141:5-46. 1947.

CARDOSO, C.O.N. Isolamento da bactéria do raquitismo (Clavibacter xyli subsp. xyli) no Brasil. Boletim Técnico COPERSUCAR 34:48-52. 1986.

CHAGAS, P.R.R. \& MATSUOKA, S. Medidas de controle do raquitismo da soqueira. Brasil Açucareiro 106 1:40-44. 1988. 
Especifidade de anti-soro policlonal contra Leifsonia xyli subsp. xyli

CIDE. Centro de Informação e Dados do Rio de Janeiro. Anuário Estatístico do Estado do Rio de Janeiro:423-424. 1999/2000.

DAVIS, M.J., GILLASPIE, A.G., HARRIS, R.W. \& LAWSON, R.H. Ratoon stunting disease of sugarcane: isolation of the causal bacterium. Science 210:1365-1367. 1980.

DAVIS, M.J., GILLASPIE, A.G., VIDAVER, A.K. \& HARRIS, R.W. Clavibacter, a new genus containing some phytopathogenic coryneform bacteria Clavibacter xyli subsp. xyli sp.nov., subsp. nov. and Clavibacter xyli subsp. cynodontis subsp. nov., pathogens that cause ratoon stunting disease of sugarcane and Bermudagrass stunting disease. International Journal of Systematic Bacteriology 34:107-117. 1984.

EVTUSHENKO, L.I., DOROFEEVA, L.V., SUBBOTIN, S.A., COLE, J.R. \& TIEDJE, J.M. Leifsonia poae. gen. nov., sp. nov., isolated from nematode galls on Poa annua, and reclassification of "Corynebacterium aquaticum" Leifson 1962 as Leifsonia aquatica (ex Leifson 1962) gen. nov., nom. rev. comb. nov. and Clavibacter xyli Davis et al. 1984 with two subspecies as Leifsonia xyli (Davis et al., 1984) gen. nov. comb. nov., International Journal of Systematic and Evolutionary Microbiology 50:371-380. 2000.

GILLASPIE, A.G. Ratoon stunting disease for sugarcane serology. Phytopathology 68: 529-532. 1978.

GIILASPIE, A.G. \& HARRIS, R.W. Limitations of ELISA for detection of the RSD - associated bacterium in sugarcane and sudangrass. Sugarcane Pathologists' Newsletter 22:25-28. 1979.

GILLASPIE, A.G., DAVIS, M.T., HARRIS, R.W. \& LAWSON, R.H. Isolation and pathogenicity of the ratoon stunting disease bacterium. International Sugar Journal 83:324-326. 1981.

GILlis, M., KERSTIRS, K., HOSTE, B., JANSSENS, D., KROPPENSTEDT, R.M., STEPHOM, M.P., TEXEIRA, K.R.S., DOBEREINER, J. \& LEY, J. Acetobacter diazotrophicus sp.nov., a nitrogen fixing acetic acid bacterium associated with sugar cane. International Journal of Systematic Bacteriology 39:361-364. 1989.

GUZMAN, M.L. \& VICTORIA K., J.I. Empleo del metodo de inmunofluorescencia directa en la detección del raquitismo de la soca (Clavibacter xyli subsp. xyli ) Fitopatologia Colombiana 17:21-30. 1993.
HARRISON, J. \& DAVIS, M.J. Infectivity titrations of Clavibacter $x y l i$ susbp. xyli and sugarcane cultivars differing in susceptibility t ratoon stunting disease. Plant Disease 70:556-558. 1986.

HARRISON, J. \& DAVIS, M.J. Comparison of serological techniques for diagnosis of ratoon stunting disease. Sugar Cane, Port Talbot : 5-9 (Resumo em CAB Abstracts on CD-ROM, v. 3A, 1990-91). 1990.

JAMES, E.K., OLIVARES, F.L., REIS, U.M., BALDANI, J.I. \& DOBEREINER, J. Infection of sugarcane by the nitrogen-fixing bacterium Acetobacter diazotrophicus. Journal of Experimental Botany 45:757-766. 1994.

OLIVEIRA, A.L.M. Contribuição da fixação biológica de nitrogênio por bactérias diazotróficas endofíticas na cultura da cana-de-açúcar: avaliação da interação entre espécies de relevância agronômica com a planta hospedeira. (Tese de Mestrado) Rio de Janeiro. Universidade Federal Rural do Rio de Janeiro. 2000.

OLIVARES, F.L., JAMES, E.K., BALDANI, J.I. \& DOBEREINER, J. Infection of Mottled Stripe disease Susceptible and Resistant Sugar Cane Varieties by Endophytic Diazotroph Herbaspirillum. New Phytologist 135:723-737. 1997.

RODRIQUES NETO, J., MALAVOLTA JR., V.A. \& VICTOT, O. Meio simples para isolamento e cultivo de Xanthomonas campestris pv. citri TIPO B. Summa Phytopathologica 12:16. 1986. (Resumo)

SANGUINO, A. Diagnóstico e controle do raquitismo da soqueira causado pela bactéria Clavibacter xyli subsp. xyli STAB, Açúcar, Álcool e Subprodutos 17:26. 1998. (Resumo)

SANGUINO, A., MORAES, V.A. \& SANTOS FILHO, O.T.D. Diagnóstico do raquitismo da soqueira em colmos de cana-de-açúcar. Anais do Seminário de Tecnologia Agronômica 2:250-253. 1984.

TARRAND, J.J., KRIOG, N.R. \& DOBEREINER, J. A taxonomy study of the Spirillum lipoferum (Beijernck) comb. nov. and Azospirillum brasilense sp.nov. Canadian Journal of Microbiology 24:967-980. 1978.

VEIGA, F.M. Notas sobre o raquitismo das socas em Campos. Brasil Açucareiro 47:81-83. 1956. 